\title{
Shattering the Myth
}

Bruce B. Lawrence, Princeton: Princeton University Press, 1998, 237 pp.

Shattering the Myth is a claim by Bruce B. Lawrence at severing the almost inextricable link, in western perceptions, between Islam and violence. Lawrence's argument is simple and seemingly straightforward, although, as he professes, at odds with most popular and academic understandings of Islam. Comprehending Islam, as he puts it, requires a clear discernment of its integrated metaphysical and circumstantial dimensions which over time has given rise to distinct forms of Islamic sociopolitical manifestations. Changing global conditions in the economic sphere have further propelled new forces and sociopolitical actors onto the public scene. Thus women may be expected to play a different and more important role in Muslim civic space in the near future. This changing role of women serves to offer hope, rather than despair, about the role of Islam in the 21 st century (p. 3 ).

Through a deconstructive process of reversal and re-inscription, Lawrence attempts to expose the privileged violent/peaceful male/female violence hierarchy that supports and justifies such perceptions of Islam. To reverse the first hierarchy and 'disconnect' Islam from violence (p. 9) he adopts a double stratagem, one definitional, the other discursive. In the former, Islam, as well as being a religion, is stressed as a modern day ideology subordinated to that of nationalism-nationalism doing for the modern era what religion did or tried to do, in premodern times (p. 15). In the second strategy Lawrence discourses through the violent colonial legacy perpetrated by the West and its brutal impact on its victims (pp. 9-10).

To reverse the second hierarchy, Lawrence, less candidly, stresses a feminist perspective. Whereas the Muslim 'enemy' is invariably depicted in Western stereotypes as a 'male' warrior from the past or a modern-day 'male' terrorist (p. 5), the feminist re-inscription depicts women as an "index of Muslim identity." The purpose is to include a perspective on Muslim women that adds complexity to the typical rendition of Muslim norms and values (p. 6). Lawrence seeks to reconstruct the 'determinist' interpretations of Islam, pertaining to violence and the subjugation of women, and to link it to the Western colonial era. The logic is that by reversing and reconstructing certain violent hierarchical categorizations so as to transform particular Western understandings and perceptions and hence attitudes toward Muslims, the latter may become less inclined to react defensively or violently. This would allow for a broader more peaceful exploratory interdisciplinary, international, cross-cultural approach (p. 12). In this sense and throughout his work, Lawrence subordinates and marginalizes Islam in favor of three determining, competing, and challenging 
'metaphysical' forces-history, nationalism, and economism. These forces of colonial and postcolonial reverberations comprise sources of constant stress rendering Muslims' identity in a perpetual state of flux where the symbolic sources of Islam become both, shared and debated, rather than just shared (p. 28 ). The outcome manifests itself in the overlapping reactive and defensive sociopolitical forms of revivalism, reformism, and fundamentalism.

Revivalism, reformism, and fundamentalism constitute three varied reactions to European domination, colonialism and dependency. All three are represented as "historically specific socioreligious movements propelling a few male leaders into public view as they attempt to reclaim the space that was challenged and reduced, then impoverished and redefined, by European expansion" (p. 40). One cannot but mark Lawrence's reference to the gender specific nature of these movements. Is it an implicit call to offer women a more dominant role or position in Muslim societies, the result of which may subsequently be less opposition and militancy in confronting Western colonialism? At face value, one cannot whether this is what Lawrence means, yet one can claim with reasonable confidence that such nuances raise additional doubts and suspicions in Muslim minds. One can further sense a reductionist and biased inclination in his representation of Islamic movements not much different from what he claims to eschew. As a matter of fact, he goes as far as stating that what matters most to Muslims is not Palestine, and thus implicitly also not Jerusalem, but economics and the uneven distribution of global resources (p. 35)-religion simply being a residual component. In such claims one can observe a strong element of economic determinism going hand in hand with historicism and perhaps even, imperialism. This is particularly the case when Lawrence asserts that no real revolution has succeeded in the Muslim world, including Iran; the measure of success is the global socioeconomic order, and economic privilege as the criteria that limits and constrains options of selfexpression (p. 37-38). Thus tradition is falsely invoked to create a form of gender asymmetry limiting the public space that women can occupy, concealing in reality structural trepidation about job scarcity and unemployment (p. 38). The extent to which such statements are falsifiable however, is moot. After all, the Arab Gulf sheikdoms continued to limit the role of women in public despite the large-scale importation of foreign workers, skilled and unskilled, to fill acute labor shortages created by their once booming economies. Was this a matter of tradition, economics, or both? This may further be compared with the increasing public role that women play in Egypt and interestingly enough, Iran. Female university students constitute a significant proportion of the total number of students, despite acute economic and unemployment problems facing both countries. Yet, in Lawrence's analysis, 'socioeconomism' remains the 
privileged indicator for a much more complex and multidimensional problem in the frame of which it is difficult to determine with reasonable accuracy where tradition ends and economics start. Furthermore, Lawrence emphasized the structural constraints superimposed by a European system of 'states,' resulting in Muslims being constituted as 'self-evident' states. According to Lawrence, this large-scale process of state construction requires more attention than the specific form by which some groups were placed within a certain state, others displaced from a state, or others denied their own identity altogether (p. 39). Perhaps, but in effect Lawrence denies Muslims agency for their own future and denies their ability to influence others, which is something he carefully disclaims or at least questions from the outset (p. 26-27).

Within this overall 'feminist' perspective, Lawrence argues that gender asymmetries are reinforced by structural limitations within the system of nation-states. In the final analysis, "the integration of women in the wage-labor force hangs on a solution to the ... economic crisis. This in turn depends on the political will to achieve real national independence and regional selfreliance" (p. 129). But if the system of nation-states is essentially the cause of inhibiting structural limitations, as Lawrence indicates in much of his work, the idea of real national independence can very easily become a contradiction in terms. His argument basically justifies 'fundamentalist' claims against the nation-state, even if they constitute a male representation of women. The problem no longer becomes a feminist issue of empowerment, but a much broader global challenge related more to the external environment than to the domestic forces of Islam, fundamentalism, or patriarchy.

Yet the status of women is crucial in the 'fundamentalist' discourse, as an ideology of control (p. 139), with laws governing women that provide the touchstone for Islamist identity (p. 138). As a system of symbols, according to Lawrence, the Qur'anic scriptures, not unlike the Bible and the Torah, lend themselves to multiple, often conflicting, extrapolations of their legal mandates (p. 139). Ignoring principles of self-referentiality, even when there are seemingly conflicting juristic rulings, he identifies the starting point of comprehension of the several manifestations of Islam to be region specific, with ideologues traced to specific countries and then sorted out into specific classes, and specific groups of men and women (p. 149). Not withstanding the insights and merits that such an analytical method may provide, it incorporates inherent faults that break down and compartmentalize wholes into their constituent parts, and then ultimately fail to piece them together. The outcome, as far as Muslims are concerned, can only be increased fragmentation, manifested earlier in terms of competing nation-states, now to be extended to family ties breaking them down into mere independent gender relations rather than col- 
lective family identities. The basic problem with a feminist approach is that analytical gender perspectives reduce the smallest unit in Muslim societies from family to the individual. This tears at the symbiotic fabric of cooperative obligation-prone socioreligious relations in favor of competing rights-prone vertical or horizontal gender relations. To the extent that women constitute a crucial matter in fundamentalist discourse, it has perhaps more to do with Muslims', and not necessarily only fundamentalist, perceptions of the next step in western discourse. Having undermined and fragmented Islamic institutions and polities, this discourse now proceeds to accomplish the same regarding the basic unit of Muslim society through a pretentious advocacy of women's rights. It does not suffice therefore to depict any one negative case related to any particular woman to justify an epistemological reversal of Lawrence's type. To the extent that 'reform' is required, it will have to be in light of consolidating the family structure, not setting women as the "index of Muslim identity." After all, what in Islam bestows this privilege on women? Lawrence provides no self-referential scriptural support.

In the same vein, in the book's conclusion Lawrence proceeds to tamper with time-cherished conceptions of jihad in favor of material considerations. Unlike the conventional understanding of the principle by West Asian Muslims as a 'holy war' against 'infidels,' Lawrence introduces a supposedly Southeast Asian (read: Malay) understanding of jihad that is economic (p. 155). He makes the analytical distinction between jihad as an Islamic principle, and corporate culture as a Southeast Asian technical construct related to competitive business in the high-tech field. Both, according to Lawrence, address the central question of his book: How can Muslim countries in the postcolonial, post-Cold War era move from confrontation to accommodation (p. 157)? Lawrence's answer is embedded in economism. For Malays, and Muslims in general, the future may yet belong to those who learn to wage economic jihad (read: corporate culture) (p. 185). Among Malay Muslims, jihad is by-passed and therefore rendered almost irrelevant by the need to situate Islam in the context of international economics (p. 158-159). However, apparently written before the dramatic changes which have taken place in Indonesia, such an analysis fails to explain the calls for jihad made by some Indonesian (Malay) Muslims once the integrity of their country had been threatened. The fact that the principle was latent due to circumstances does not justify Lawrence's observations. If Malaysia feels its physical security threatened, it is fair to say that the dormant principle in its original meaning and manifestation will experience a renaissance. In West Asia, the principle has continued to actively resonate due to the security threats that confront the region, ranging from that of Israel to the American virtual colonization of the region. Therefore, circumstances, not the inherent 
meaning of jihad, is different. Jihad at its core, and irrespective of any diverse manifestations, is related to defending the faith. Economic jihad is legitimate to the extent that it serves Islamic values rather than having Islamic values serve economics. The latter condition is the inevitable outcome if Islam is to be contextualized in the global system. The nature of the problem thus is much more complex than Lawrence seems to acknowledge. In effect, he appears to be adopting the same epistemology, which historically had contextualized Christianity into Roman paganism, producing comsequently the myth of the human-God. The difference now is that Islam is supposed to be contextualized in a different form of paganism, that of economism and globalism, producing ultimately the myth of homo-economicus-God. In the same fashion that revelatory Christianity lost its essence, so would Islam, or at least so would be the expectation. In one stroke, Islam becomes both Christianized and secularized suffering as a consequence the ultimate defeat, when it is its inherent mission to challenge such mythical constructs-such is the purpose of jihad.

Shattering a myth, any myth, especially one created, elevated and fed upon by global strategic and political interests, is a consistently challenging enterprise. Once articulated and hegemonic, myths become discourses of power and domination, the confrontation of which implicates and engages vested interests, opposing currents and consolidated, well fortified status quo forces of 'order.' These considerations appear to be of major concern to Lawrence and his project, as he attempts to tread into the highly charged territory of Islam, Islamic movements and violence. It remains unclear throughout his work as to which myth or myths he is seeking to shatter-whether he seeks to shatter myths about Islam, the myth of Islam, or both. Lawrence appears to have attempted to accomplish the former through the second in much the same way the proverbial bear kills its master. By privileging economic epistemology over Islamic normative ontology, reversing and representing the latter in the framework of the former, he undermines and actually almost eliminates the very subject or category he is alleging to represent. By claiming the existence of many Islams rather than one, rendering the True Islam an unknown category, the unifying and consolidating dimensions of the faith are undermined. For if there are many Islams, would the concept of a one and unique 'Ummah' (Islamic community; Qur'an $21: 92 ; 23: 52$ ) really make any sense? Would not a crucial Islamic category, among others, be simply dissolved? Clearly, this is what Lawrence is aiming at (p. 149-156) - shattering the 'myth' of the the Ummah.

Even when dealing with the case of the Islamic revolution in Iran, Lawrence seeks to dilute and hence cast doubts not only on its Islamic nature and credentials, but further, at the very fact that it is a revolution or that Islam is capable of such profundity. He poses the question "did 
1978-79 produce an Islamic revolution?" (p. 94). His answer comes as an equivocal no and yes. No, because it was also a Third World revolution; yes, because Islam was the label through which a Shi'a Iranian monarchy was replaced with an Iranian-Shi'a theocracy (note his stress on Iranianism and Shi'ism rather than on Islam-the latter being only a label). He then proceeds to cast further doubt on its revolutionary impact by stressing that little has been done on the crucial issue of land reform since the time of the Shah. Land reform constituting "the most evident single issue for gauging how difficult it is to implement a genuine social revolution in Iran" (p. 98). Yet by the same token, Lawrence states that despite the high-sounding claims made by and about President Gamal Abdul Nasser of Egypt, the country did not experience either a social or an economic revolution under his rule (p. 64). But if land reform is such an important index of social revolution, did not Egypt actually undergo a massive and largely successful land reform under his regime? More superficially, he identifies Iran as the standard reflection of male-specific Islamic fundamentalism (p. 112). He fails to reflect on the profundity of this revolutionary experience as the historical synthesis of revivalism, reformism and fundamentalism, which, as such, constitutes something more than all three. Essentially, it combined all elements of restoration, ijtihad, and "nontraditional advocacy of traditional norms," i.e., fundamentalism (p. 148). Yet this is an issue that he almost totally ignores or does not seem to be aware of. In many respects Lawrence's work reiterates and reflects the confused state of Western scholarship as it wheels and deals with Islam in the free-market of ideas and opinions, unconstrained by the self-referential logic and structure of the faith itself. From where he does not know, Lawrence confirms the Qur'anic prophecy: "Never will the Jews or Christians be satisfied with thee unless thou follow their form of Religion" (2:120).

Amr Sabet Department of Political Science University of Tampere Finland 